\title{
A career in orthopaedics
}

\author{
Andreas F. Mavrogenis ${ }^{1} \cdot$ Marius M. Scarlat $^{2} \cdot$ Cyril Mauffrey $^{3} \cdot$ \\ Pierre Kehr ${ }^{4}$
}

Received: 14 June 2017/ Accepted: 15 June 2017/Published online: 21 June 2017

(C) Springer-Verlag France SAS 2017

With a lot of commitment to their studies and an idyllic charm, enthused high school students succeed the School of Medicine. After 2 years in amphitheatre lessons, they finally begin clinical rotations. With emphasis on training and caring for patients, they willingly sacrifice a lot of personal hobbies and interests. They are motivated and enthusiast, often faced with pessimism for the future, and less often with inattention, cynicism and disregard. After a lot of sacrifices and stress, the medical students graduate the School of Medicine. Some graduate with honours and with a high scholastic talent, mechanical ability and manual dexterity, they decide to follow a career in orthopaedics and enter an orthopaedic training programme.

During the orthopaedic residency programme, most residents are initially enthusiastic by the knowledge, expertise and judgment of their senior residents, professors and heads of departments. Little time exists outside hospital; amalgamated with the phobia of burnout, most of time is spent in hospital duties, auditoriums and seminars, or studying the bibliography, surgical approaches and techniques. Some residents form strong bonds with colleagues, consultants and professors and generate a dynamic synergy; some are blessed to be trained by experts, mentors and leaders. They are introduced to journals and

Andreas F. Mavrogenis

afm@otenet.gr

1 First Department of Orthopaedics, National and Kapodistrian University of Athens, School of Medicine, 41 Ventouri Street, Holargos, 15562 Athens, Greece

2 Clinique St. Michel, Toulon, France

3 Department of Orthopaedics, Denver Health Medical Center, Denver, CO, USA

4 AREDEJOST, Strasbourg, France international memberships; they are invited by prestigious editors and start reviewing and writing. These help to build the basis for a prolific career. The residents finally achieve orthopaedic licensure; some find caring for patients with cancer particularly rewarding and decide to pursue a fellowship in orthopaedic oncology; others are enthusiastic by trauma, shoulder or spinal surgery and have opted for a respective fellowship and subsequent practice [1].

At fellowships, they meet important people, build dynamic friendships, study hard and write a lot to share knowledge. Then, they meet wonderful people, prestigious editors from the international medical community; they introduce them to their journals and invite them to their reviewers' panels and editorial boards. They help them "to stand on the shoulders of giants, to see more and farther than predecessors, not because of keener vision or greater height, but because they are lifted up and borne aloft on their gigantic stature" [2-4]. At the end of fellowship, they join a prestigious practice. However, the discipline is challenging, demanding, consuming and rewarding. Balancing personal and professional life is a common challenge for surgeons; family is often overlooked [5-9]. Financial success, international fame and recognition and personal interests/family are competing interests. Identifying personal values and protecting personal time are necessary to achieve work-life balance [1, 10-12].

Orthopaedics is a medical specialty that focuses on the diagnosis, care and therapy of patients with disorders and syndromes of the musculoskeletal system. Diagnostic methods and aetiological therapies of traumatic, nonphysiological and pathological syndromes, pharmacologic and prophylactic therapeutic policies and targeted therapeutic schemes synthesize an enthusiastic orthopaedic practice. A giant anode has occurred in European propaedeutics and academics in orthopaedics and 
traumatology within the last 3-4 decades. A plethora of residency programmes, competitive fellowships and clinical rotations, academic symposia and prolific research and educational activity on basic and didactic themes in the sphere of orthopaedics and traumatology are available. There are many areas of special interest that orthopaedic surgeons can emphasize their practice such as trauma and poly-trauma of the musculoskeletal system, arthroscopic and arthroplasty surgery, paedo-orthopaedics, podiatric surgery, carpus and dactylic surgery with traumatic and genetic anomalies, microsurgery, spondylopathies like scoliosis, kyphosis and spondylolisthesis, osteoporosis and pharmacologic and orthopaedic oncology [13]. In 1741, Nicholas Andry de Bois-Regard coined the word "orthopcedics" in French as orthopédie, derived from the Greek words orthos (ỏp $\theta$ ós "correct", "straight") and paidion ( $\pi \alpha 1 \delta$ íov "child"), since much of the early work in orthopaedics involved treating children with skeletal anomalies [14]. Currently, orthopaedic surgeons continue to treat children. Some confine their practice to specific areas of the musculoskeletal system. In a future era of subspecialization, probably we will be faced with orthopaedic surgeons practicing on a specific bone, fracture type, or syndrome [13].

Orthopaedic oncology has its roots in European medicine of the 1800s where sarcomas were first classified on the basis of their gross characteristics (1804) and amended on the basis of their histologic features (1867). Local surgical treatment has been related to unacceptable mortality and led to amputation (1870s) and remained so until limbsparing resection was cautiously embarked (mid-1900s). Introduction of adjuvant therapies (1880s) remained largely ineffective until the advent of (neo-) adjuvant chemotherapy (1970s). Pragmatically, in the past 40 years, the amalgamation of these techniques enhanced by orthopaedic oncology fellowships, societies and regional cancer centres has led to current preponderance of limb-salvage surgery and greatly improved survival rates $[15,16]$.

In this special issue, current orthopaedic oncology practice is reviewed in papers written with the scope of a non-dogmatic and egocentric dialogue by polyethnic orthopaedic physicians, experts in orthopaedic oncology. Dedicated to continuous medical education, the authors provide educational manuscripts with state-of-the-art techniques, innovations and modifications of the traditional therapies, commentaries and illustrations that are expected to be extremely helpful in decision making in clinical practice. Research remains the most important aspect for the patients; it begins from and returns to the patients. In the next years, more advances and innovations are expected in diagnostic imaging, minimally invasive treatments, metallurgy of implants, allografts and chemotherapy agents. Better metrics for measuring outcome should clarify how effective these would be for the patients' outcome.

\section{Compliance with ethical standards}

Conflict of interest No benefits have been or will be received from a commercial party related directly or indirectly to the subject matter of this article.

\section{References}

1. Shanafelt $\mathrm{T}$ (2008) a career in surgical oncology: finding meaning, balance, and personal satisfaction. Ann Surg Oncol 15 (2):400-406

2. Newton I (2016) Letter from Sir Isaac Newton to Robert Hooke. Historical Society of Pennsylvania. Retrieved 7 Aug 2016

3. MacGarry DD (ed) (1955) The Metalogicon of John Salisbury: a twelfth-century defense of the verbal and logical arts of the Trivium (trans: MacGarry DD). University of California Press, Berkeley, p 167. Retrieved 29 April 2016

4. Merton RK (1965) On the shoulders of giants: a shandean postscript. Free Press, New York City

5. Kent GG, Johnson AG (1995) Conflicting demands in surgical practice. Ann R Coll Surg Engl 77:235-238

6. Ramirez AJ, Graham J, Richards MA et al (1995) Burnout and psychiatric disorder among cancer clinicians. $\mathrm{Br} \mathrm{J}$ Cancer 71:1263-1269

7. Green A, Duthie HL, Young HL, Peters TJ (1990) Stress in surgeons. Br J Surg 77:1154-1158

8. Whippen DA, Canellos GP (1991) Burnout syndrome in the practice of oncology: results of a random survey of 1000 oncologists. J Clin Oncol 9:1916-1920

9. Kuerer HM, Eberlein TJ, Pollock RE et al (2007) Career satisfaction, practice patterns, and burnout among surgical oncologists: report on the quality of life of members of the Society of Surgical Oncology. Ann Surg Oncol 14:3043-3053

10. Weiner EL, Swain GR, Wolf B, Gottlieb M (2001) A qualitative study of physicians' own wellness-promotion practices. West J Med 174:19-23

11. Quill TE, Williamson PR (1990) Healthy approaches to physician stress. Arch Intern Med 150:1857-1861

12. Shanafelt T, Novonty P, Johnson ME et al (2005) The well-being and personal wellness promotion strategies of medical oncologists in the north central cancer treatment group (NCCTG). Oncology (Karger) 68:23-32

13. http://orthoinfo.aaos.org/topic.cfm?topic=A00274. Accessed 13 June 2017

14. Andry de Bois-Regard N (1743) Orthopædia, or, the art of correcting and preventing deformities in children, 1980. Classics of Medicine Library, Birmingham

15. Enneking WF (2000) An abbreviated history of orthopaedic oncology in North America. Clin Orthop Relat Res 374:115-124

16. Enneking WF (2009) History of orthopedic oncology in the United States: progress from the past, prospects for the future. Cancer Treat Res 152:529-571 